\title{
Cerebrovascular complication of infective endocarditis complicated with abdominal trauma
}

\author{
Başak Akyıldız ${ }^{1}$ Nazan Ülgen-Tekerek ${ }^{1}$, Abdullah Özyurt² ${ }^{2}$ Özge Pamukçu ${ }^{2}$, Nazmi Narin ${ }^{2}$ \\ Departments of ${ }^{1}$ Pediatric Intensive Care, and ${ }^{2}$ Pediatric Cardiology, Erciyes University Faculty of Medicine, Kayseri, Turkey. \\ E-mail: basaknurbesra@gmail.com \\ Received: 25th January 2016, Revised: 9th May 2016, Accepted: 10th June 2016
}

SUMMARY: Akyıldız B, Ülgen-Tekerek N, Özyurt A, Pamukçu Ö, Narin N. Cerebrovascular complication of infective endocarditis complicated with abdominal trauma. Turk J Pediatr 2016; 58: 554-557.

A 9-year-old boy presented to the emergency department with blunt abdominal trauma. Initial assessment was normal except for abdominal tenderness. On day 3, patient was transferred to the pediatric intensive care unit (PICU) for hemodynamic instability, and persistent fever despite antibiotic therapy. On PICU admission, his body temperature was $40{ }^{\circ} \mathrm{C}$, heart rate was $160 / \mathrm{min}$, respiratory rate was $36 / \mathrm{min}$, blood pressure was $85 / 40 \mathrm{mmHg}$, and impaired consciousness was noticed. Complete blood count revealed hemoglobin of $11.5 \mathrm{~g} / \mathrm{dl}$, white blood cell count of $22,500 / \mathrm{mm}^{3}$ and platelet count of $145,000 / \mathrm{mm}^{3}$. Serum C-reactive protein and procalcitonin were $139 \mathrm{mg} /$ $\mathrm{dl}$ and $8.80 \mathrm{ng} / \mathrm{ml}$, respectively. Renal and liver function test results were normal. Cranial magnetic resonance imaging (MRI) was planned because of impaired consciousness and fever. On cranial MRI, multiple infarct areas were detected in both hemispheres and minimal hemorrhagic focus was found in the left temporal region. Because of the cranial MRI findings and fever echocardiographic examination was planned to exclude infective endocarditis. Transthoracic echocardiography successfully visualized mitral valve prolapse, $14 \times 8 \mathrm{~mm}$ mobile vegetation on the atrial side of the posterior leaflet of the mitral valve, and severe mitral regurgitation. The left chambers were dilated. There was no evidence of a perivalvular abscess. On control transthoracic echocardiography, after 6 weeks of parenteral antibiotic treatment, there was no significant reduction of the visible vegetation therefore surgery was planned. Infective endocarditis should be considered in the differential diagnosis of fever of unknown origin. Especially during the early stage of disease, cranial MRI may be more useful to prevent fatal complications for patients with neurologic examination findings.

Key words: infective endocarditis, magnetic resonance imaging, cerebrovascular complication.

Infective endocarditis (IE) with an estimated rate of $0.34-0.64$ cases per 100,000 per year, is considered as an uncommon disease in childhood $^{1}$. However, its higher rates of morbidity and mortality despite of long-term parenteral antibiotic treatment and related complications make it a serious disease in children ${ }^{2,3}$. The most significant complications of IE are congestive heart failure and cerebrovascular complications (CVC). CVC frequently occur in patients with the active stage of IE, and result from septic embolization of endocardial vegetation. CVC are generally accepted as a poor predictors of prognosis, and patients with IE have increased mortality ${ }^{1,3}$. In this case, we present CVC of IE complicated by blunt abdominal trauma.

\section{Case Report}

A 9-year-old boy was referred to the pediatric surgery clinic with blunt abdominal trauma. It was learned that the patient lost consciousness and fell in the bathroom 2 days previously. He had no fever or systemic symptoms of chills or poor appetite before this incident. On the physical examination, all vital signs 
were normal except for abdominal tenderness. Cranial computed tomography (CT) revealed a contusion in the left temporal region and abdominal CT showed a laceration on the spleen and posterior aspect of the right kidney. The patient was transferred to the pediatric intensive care unit (PICU) on day 3 for hemodynamic instability, and persistent fever despite antibiotic therapy. On PICU admission, his body temperature was $40^{\circ} \mathrm{C}$, heart rate was $160 / \mathrm{min}$, blood pressure was $85 / 40 \mathrm{mmHg}$, respiratory rate was $36 / \mathrm{min}$ body and impaired consciousness was noticed. Complete blood count revealed hemoglobin of $11.5 \mathrm{~g} / \mathrm{dl}$, white blood cell count of $22,500 /$ $\mathrm{mm}^{3}$ and platelet count of $145,000 / \mathrm{mm}^{3}$. Serum C-reactive protein and procalcitonin levels were $139 \mathrm{mg} / \mathrm{L}$ and $8.80 \mathrm{ng} / \mathrm{ml}$, respectively. Renal and liver function test results were also normal. On cranial MRI, multiple infarct areas were detected in both hemispheres and there was minimal hemorrhagic focus in the left temporal region; these results were different from those found on cranial CT (Figs. 1 and 2). Because of cranial MRI findings and persistent fever, echocardiographic examination was planned to exclude IE. Transthoracic echocardiography successfully visualized mitral valve prolapse, mobile $14 \times 8 \mathrm{~mm}$ vegetation on the atrial side of the posterior leaflet of the mitral valve, and severe mitral regurgitation. The left chambers were dilated (Fig. 3). Serial blood culture detected Staphylococcus aureus (S. aureus). There was no evidence of a perivalvular abscess. After 6 weeks of parenteral antibiotic treatment, control transthoracic echocardiography showed no significant reduction in the visible vegetation; therefore, surgery was planned.

\section{Discussion}

The true incidence of neurologic complications is difficult to assess because few studies used systematic neuroimaging. Cranial MRI is necessary to facilitate diagnosis, especially during the early stage, and reveal cranial lesions in IE. MRI revealed broader involvement of the brain than indicated by clinical signs and/or CT $\operatorname{scan}^{4,5}$. MRI also permitted better evaluation of the embolic nature of the vegetation ${ }^{6}$.

In our patient, fever and impaired consciousness were more important clinical findings, as was abdominal blunt trauma. Fever, possibly lowgrade and intermittent, is present in $90 \%$ of patients with $\mathrm{IE}^{7}$. However, heart murmurs are found in up to $85 \%$, and new murmurs have been recently reported in $48 \% 7,8$. The diagnosis of IE should also be considered for

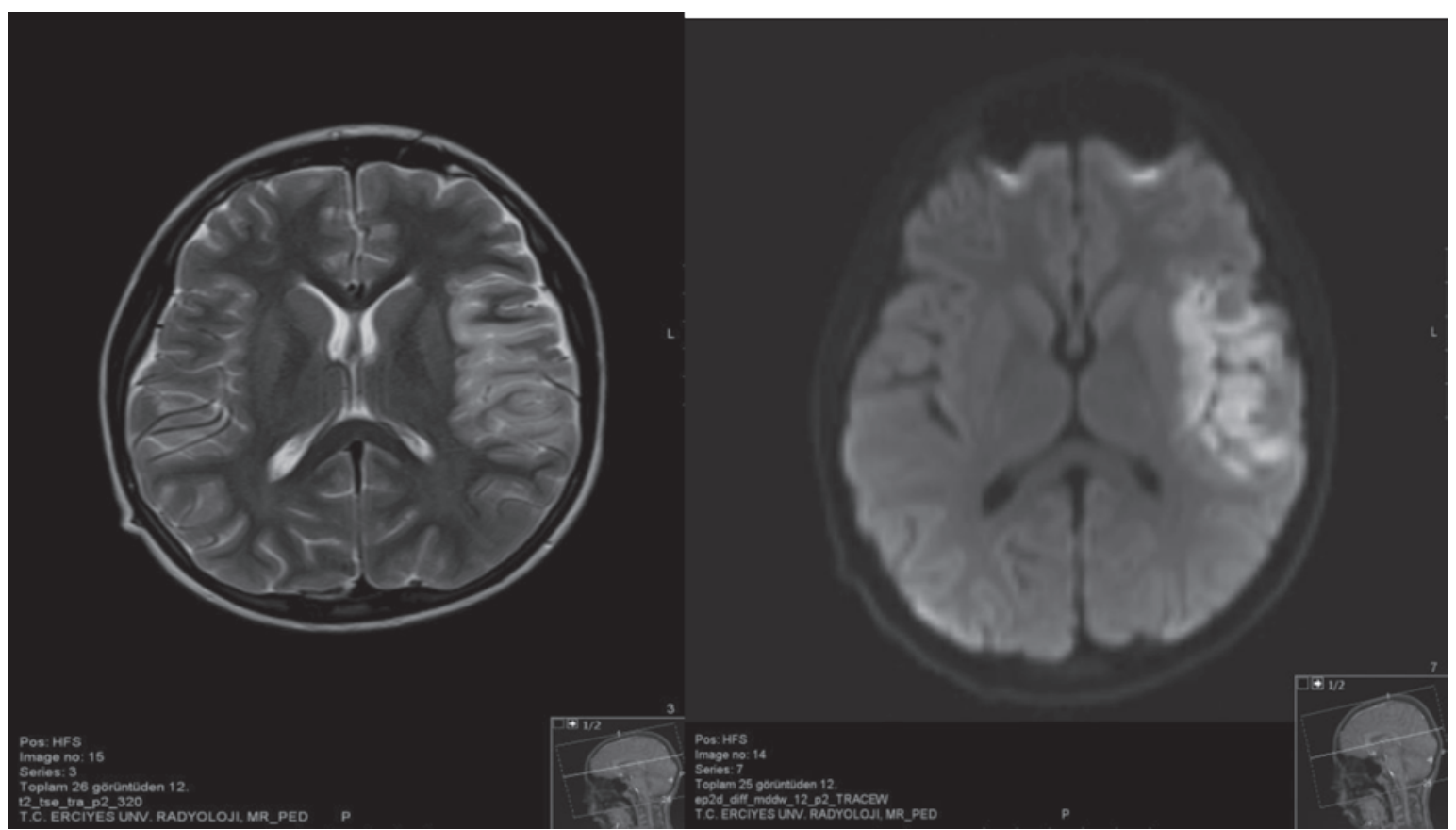

Fig. 1-2. Multiple infarct areas were detected in both hemispheres and minimal hemorrhagic focus in the left temporal region in $\mathrm{T} 2$ and diffusion weighted imaging. 


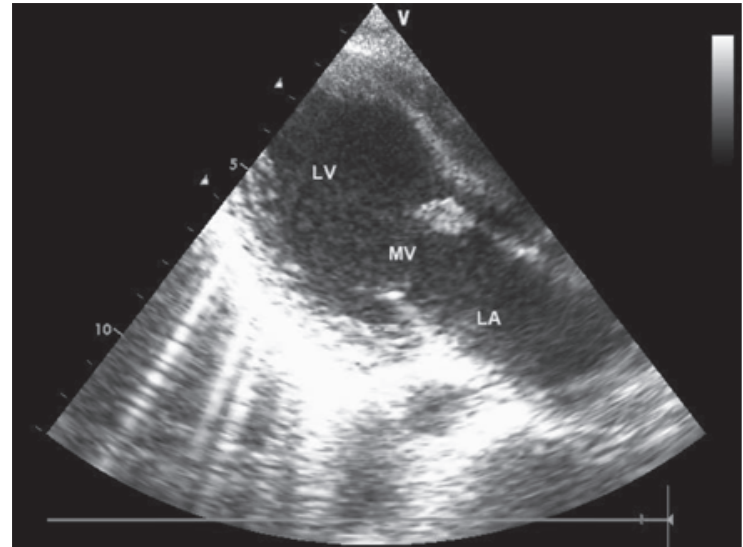

Fig. 3. Transthoracic echocardiography successfully visualized mitral valve prolapse: $14 \times 8 \mathrm{~mm}$ mobile vegetation on the atrial side of the posterior leaflet of the mitral valve, and severe mitral regurgitation

patients with a stroke or transient ischemic attack and fever, as in our case. We performed cranial MRI to evaluate neurologic dysfunction in detail. On cranial MRI, multiple infarct areas detected in both hemispheres and minimal hemorrhagic focus in the left temporal region were viewed differently than on cranial CT. Because of these findings, we performed echocardiographic examination and detected mitral valve prolapse, $14 \times 8 \mathrm{~mm}$ mobile vegetation on the atrial side of the posterior leaflet of the mitral valve, and severe mitral regurgitation. Mitral valve prolapse is the one of most common heart diseases predisposing to infective endocarditis ${ }^{9,10}$.

Patients with IE are generally referred to the intensive care unit for one or more organ dysfunctions caused by complications of IE, as in our case. Neurologic complications such as stroke, transient ischemic attack, bacterial meningitis and cerebral embolism are the most severe extracardiac complications of $\mathrm{IE}^{6,11}$. Many of these occur early during the course of IE and are considered major risk factors for increased mortality and morbidity. Therefore, early diagnosis and appropriate medical treatment are essential ${ }^{11-13}$. We diagnosed IE on the first day of intensive care hospitalization (the third day of admission).

The timing of surgery for IE sometimes may be difficult to determine. Embolic complications may be seen during any stage of IE; they mostly occur before diagnosis or within 2 weeks after diagnosis. Several studies performed in relation to the timing of surgery have confirmed that embolic risk decreases dramatically during or after the first 2 to 3 weeks of successful antibiotic therapy ${ }^{14-16}$.

The International Collaboration on Endocarditis demonstrated that the incidence of stroke in patients receiving appropriate antimicrobial therapy was $4.8 / 1000$ patient-days during the first week of therapy; this decreased to $1.7 / 1000$ patient-days during the second week and became lower thereafter ${ }^{17}$. Our patient's vital signs and clinical situation remained stable after starting antibiotic treatment; therefore intervention was postponed in the short term to allow a brief period of antibiotic therapy under careful clinical and echocardiographic observation.

The rate of IE related CVC is increased in patients with $S$. aureus and fungal infection, vegetation $>1 \mathrm{~cm}$, and mitral valve IE such as in our patient. Early and prompt initiation of antibiotic therapy has been the most effective therapy to reduce the rate of the septic embolism ${ }^{12}$.

In conclusion, IE may present with many different scenarios and sometimes may be masked by other symptoms, as in our case. Therefore, IE should be taken into consideration in the differential diagnosis of fever of unknown origin to prevent fatal complications.

\section{REFERENCES}

1. Knirsch W, Nadal D. Infective endocarditis in congenital heart disease. Eur J Pediatr 2011; 170: 1111-1127.

2. Ferrieri P, Gewitz MH, Gerber MA, et al. Unique features of infective endocarditis in childhood. Circulation 2002; 105: 2115-2126.

3. Lengyel M. Diagnosis, treatment and prevention of infective endocarditis. Orv Hetil 2010; 151: 613-620.

4. Cooper HA, Thompson EC, Laureno R, et al. Subclinical brain embolization in left-sided infective endocarditis: results from the evaluation by MRI of the brains of patients of patients with left-sided intracardiac solid masses (EMBOLISM) pilot study. Circulation 2009; 120: 585-591.

5. Novy E, Sonneville R, Mazighi M, et al. Neurological complications of infective endocarditis: New breakthroughs in diagnosis and management. Med Mal Infect 2013; 43: 443-450.

6. Goulenok T, Klein I, Mazighi M. Infective endocarditis with symptomatic cerebral complications: contributing cerebral magnetic resonance imaging. Cerebrovascular Disc 2013; 35: 327-336. 
7. Gould FK, Denning DW, Elliot TS, et al. Guidelines for the diagnosis and antibiotic treatment of endocarditis in adults: a report of Working Party of the British Society for Antimicrobial Chemotheraphy. J Antimicrob Chemother 2012; 67: 269-289.

8. Murdoch DR, Corey GR, Hoen B, et al. Clinical presentation, etiology and outcome of infective endocarditis in the 21st century: The International Collaboration on Endocarditis-Prospective Cohort Study. Arch Intern Med 2009; 169: 463-473.

9. Clemens JD, Horwitz RI, Jaffe CC, et al. A controlled evaluation of the risk of bacterial endocarditis in persons with mitral-valve prolapse. $\mathrm{N}$ Engl J Med 1982; 307: 776-781.

10. Nishimura RA, McGoon MD. Perspectives on mitralvalve prolapse. N Engl J Med 1999; 341: 48-50.

11. Lee SJ, Oh SS, Lim DS, Na CY, Kim JH. Clinical significance of cerebrovascular complications in patients with acute infective endocarditis: a retrospective analysis of a 12-year single-center experience. BMC Neurol 2014; 14: 14-30.

12. Snygg-Martin U, Gustafsson L, Rosengren L, et al. Cerebrovascular complications in patients with leftsided infective endocarditis are common: a prospective study using magnetic resonance and neurochemical brain damage markers. Clin Infect Dis 2008; 47: 23-30.
13. Sonneville R, Mourviller B, Bouadma L, Wolff M Management of neurological complications of infective endocarditis in ICU patients. Ann Intensive Care 2011; 1: $10-18$.

14. Thuny F, Avierinos JF, Tribouilly C, et al. Impact of cerebrovascular complications on mortality and neurologic outcomes during infective endocarditis: a prospective multicentre study. Eur J Heart 2007; 28: $1155-1161$

15. Thuny F, Disalvo G, Belliard O, et al. Risk of embolism and death in infective endocarditis: prognostic value of echocardiography: a prospective multicenter study. Circulation 2005; 112: 69-75.

16. Vilacosta I, Graupner C, San Román JA, et al. Risk of embolization after institution of antibiotic therapy for infective endocarditis. J Am Coll Cardiol 2002; 39: 1489-1495.

17. Dickerman SA, Abrutyn E, Barsic B, et al. The relationship between the initiation of antimicrobial therapy and the incidence of stroke in infective endocarditis: an analysis from the ICE Prospective Cohort Study (ICE-PCS). Am Heart J 2007; 154: 1086-1094. 